\title{
Longitudinal Analysis of Leptin Variation during Weight Regain after Weight Loss in Obese Children
}

\author{
Jens-Christian Holm ${ }^{a, b, c}$ Michael Gamborg ${ }^{b}$ Leigh Ward ${ }^{d}$ Karsten Kaas lbsen ${ }^{a}$ \\ Steen Gammeltoft ${ }^{\mathrm{c}}$ Thorkild I.A. Sørensen ${ }^{\mathrm{b}}$ Berit Lilienthal Heitmann ${ }^{\mathrm{b}}$ \\ a Department of Pediatrics, Copenhagen University Hospital Glostrup, \\ ${ }^{\mathrm{b}}$ Institute of Preventive Medicine, Copenhagen University Hospital, Centre for Health and Society, Copenhagen, \\ ${ }^{\circ}$ Department of Clinical Biochemistry, University Hospital Glostrup, Denmark \\ ${ }^{d}$ School of Molecular and Microbial Sciences, University of Queensland, Brisbane, Australia
}

\section{Key Words}

BMI SDS · Body composition · Child · Leptin ·

Longitudinal study · Obesity · Puberty · Weight gain .

Weight loss

\section{Summary}

Objective: This study assessed if lower than predicted serum leptin concentrations seen during weight loss persisted during weight regain, with possible implications for weight control. Methods: 115 children were investigated during a 12-week weight loss program. 90 children completed the program, and 68 children entered a follow-up program spanning 28 months. Measurements were performed at baseline and day 82 as well as at months 10, 16, and 28. Height, weight, body composition, Tanner stages, testicular size, and serum concentrations of leptin, and insulin were measured at all time points. Results: Children with the greatest increases in BMI standard deviation score (SDS) exhibited the largest leptin increments. The disproportionate reduction of leptin seen during weight loss recovered after weight loss. Leptin increases mirrored increases in BMI SDS during weight regain, and the leptin-BMI SDS relationship seen during follow-up resembled the baseline leptin-BMI SDS relationship. Conclusion: Proportional increases of leptin and BMI SDS during weight regain suggests an intact leptin response during re-accumulation of fat. Following the pronounced reduction of leptin during weight loss, leptin levels were restored during weight regain to an extent where leptin levels were comparable with those at baseline, which is indicative of an inefficient lipostatic control exerted by leptin during weight regain.

\section{Introduction}

During energy deprivation, low leptin levels seem to be a potent activator of pathways associated with stimulation of feeding as well as various energy-sparing adaptations, with the net effect to re-establish a sufficient amount of energy in the energy-threatened individual $[1,2]$.

This may imply that low concentrations of leptin might contribute to a later weight gain, as suggested by Ravussin et al. [3] in Pima Indians. But mixed results persist, and Kettaneh et al. [4] and Fleisch et al. [5] reported instead that a high leptin concentration relative to fat mass at baseline predicts fat mass gain over time in children. However, methodology, approach and end points were different in these studies, making comparisons less favorable.

From a weight loss intervention study in children our group recently reported a larger than expected decrease in overall levels of leptin concentrations given the baseline leptin-weight relationship and after adjustment for later decreases in weight. This was evident despite a stable leptin-weight relationship at any of 9 given measurement points after initiation of weight loss and suggests a BMI standard deviation score(SDS)-independent effect that decreases leptin concentrations during weight loss [6]. Therefore, it is possible that weight-reduced individuals continue to exhibit the relatively lower leptin concentrations even after their weight loss, which may render them prone to a subsequent regain in weight.

Several scenarios are possible; leptin remain relatively low and promote weight regain, leptin changes simply mirror weight changes, leptin increases to an upper limit during weight regain and fail to promote its anorexic effects which may suggest leptin resistance, or leptin increases rapidly during weight regain as a lipostatic control of further weight regain.

\section{KARGER}

Fax +497614520714

Information@Karger.de

www.karger.com (c) 2009 S. Karger GmbH, Freiburg

Accessible online at:

www.karger.com/ofa 
Longitudinal studies with consecutive measurements addressing leptin changes during weight gain in children are scarce, except for reports before and after weight gain [7], or measures from studies of children with chronic diseases experiencing weight gain due to therapy, catch-up, or pharmacological side effects [8-19]. Therefore, little information exists on how leptin changes during long-term weight regain after weight loss in children with simple adiposity.

In this longitudinal study, we studied weight regain over 28 months after a significant weight loss intervention in order to examine if variations in leptin change were associated with differences in weight change in children. These observations may contribute to our understanding of the regulatory ability of leptin to maintain a lowered weight.

\section{Material and Methods}

\section{Design}

The children were examined on day 1 (baseline) and day 82 during the weight loss regimen as well as at months 10,16 , and 28 during the follow-up regimen (for data regarding day 4, 8, 14, 23, 33, 48, 66 of the intervention please see [6]). The investigation included an interview and assessment of Tanner stages (gonadal and pubertal), testicular size, weight, height, body composition by bioimpedance spectroscopy, and venous blood samples; they were carried out at every examination day. The study was approved by The Scientific Ethical Committee of the County of Copenhagen (KA 970041), and written informed consent was obtained from all participants, as well as from their parents according to the Helsinki Declaration and its latest amendments.

\section{Setting}

The institution 'Julemærkehjemmet', Skælskør, Denmark, offers weight reduction regimens consisting of low-fat diet with a fixed and restricted level of energy intake to 6,500-7,000 kJ/day, and mandatory and optional physical activity. Children stayed at the institution for 12 weeks after which they were sent home. Both parents and children were instructed to prepare low-fat meals, and to increase physical activity of the children both at home and at school. Follow-up examinations were carried out at the Pediatric Department at the University Hospital in Glostrup.

\section{Children}

During the study, 232 children were identified as eligible to participate, and 115 agreed to do so. 90 children completed the weight loss program, 68 engaged in follow-up, and 44 children completed all examinations in the follow-up program. Vigorous efforts were made in order to secure participation of included children in follow-up. However, reasons for dropout during follow-up was not recorded since those dropping out did not communicate by any means why they dropped out even though numerous letters were sent out. Examinations were re-scheduled repeatedly, and many children were examined in their own homes.

\section{Procedures}

Height was measured to the nearest $5 \mathrm{~mm}$ by stadiometer and weight to the nearest $0.1 \mathrm{~kg}$ on a SECA Delta Scale, model 707, (Simonsen and Weel, Vallensbæk Strand, Denmark). BMI SDS was calculated by the LMS method, which transforms BMI into normal distributions at each age and sex using the median and the coefficient of variation and a measure of the skewness based on the Box-Cox power. These age- and sex-specific variables were attained from growth data generated in Danish boys and girls [20]. Fat-free mass percents were determined from whole-body bio- electrical impedance measurements obtained using an SFB3 impedance spectrometer (Uniquest Ltd., Brisbane, Australia) and calculated using impedance data at $50 \mathrm{~Hz}$ only, according to the equation proposed by Schafer et al. [21]. We also applied the equation of Wabitsch et al. [22], which gave similar body composition estimates. Fat mass percents were determined by difference from body weight. Puberty was rated according to Tanner stages after evaluation of pubic hair and breasts, and testicular size was measured by Prader's orchidometer.

Venous blood samples were collected after an overnight fast from each child between 7:00 a.m. and 8:30 a.m. during the weight loss program and between 8:00 a.m. and 9:00 a.m. during follow-up. The serum was frozen at $-20{ }^{\circ} \mathrm{C}$ until analysis. Radioimmunoassay for leptin was performed in duplicate, using the Linco Human Leptin RIA Kit (Linco Research Co, St Louis, MO, USA). The inter-assay coefficient of variation was $4.0 \%$ and the intra-assay coefficient of variation was $7.6 \%$. Leptin concentrations during follow-up were compared to leptin concentrations at baseline adjusted for puberty and BMI SDS [6]. Expected leptin concentrations during follow-up were calculated based upon the relationship of BMI SDS, puberty and leptin at baseline and given changes of puberty and BMI SDS during follow-up. Expected (calculated) leptin concentrations were compared with actual (measured) leptin concentrations during follow-up.

The DAKO Insulin ELISA (DAKO Diagnostics Ltd., Ely, UK) was used, and it showed an inter-assay coefficient of variation of $7.5 \%$ and an intra-assay coefficient of variation of $6.5 \%$.

\section{Statistical Methods}

Leptin data were log-transformed in order to achieve approximate normality, variance homogeneity, and linearity. Independent variables were number of examination, BMI SDS, and log-transformed testicular size or menarche.

Leptin was modelled using a multiple linear model with correlated errors [23]. An interaction term allows to monitor changes of the association between leptin and BMI SDS over time and to compare associations at later examinations with that at baseline.

In order to avoid bias originating from the missing observations during the longitudinal analysis, we chose an unstructured model for covariance [24].

Possible selection bias due to subject dropout was evaluated by testing whether subjects who have dropped out differed from those completing the study with respect to age and adiposity. In order to detect a possible bias due to dropout, statistical re-analysis excluding those with missing investigations was performed.

Pearson partial correlation coefficients $(r)$ between log-transformed leptin and BMI SDS adjusted for insulin and puberty were calculated.

\section{Results}

At baseline 53 boys and 62 girls were included in the weight loss regimen 90 of whom completed the treatment. 68 of these children were included in the follow-up regimen which was completed by 44 children, yielding retention rates of $78 \%$ during the weight loss regimen and of $65 \%$ during the follow-up. There were no differences in baseline age $(p=0.54)$, or BMI SDS $(\mathrm{p}=0.74)$ between children included in the analysis and those dropping out during the program. The group has been described in detail at baseline previously [6].

At baseline median ages were 12.1 years in both genders, with a range of 7.9-14 years in boys and of 8.5-15.2 years in girls. Median gonadal and pubertal Tanner scores were 2, median testicular volumes were $3.25 \mathrm{ml}$, and 21 out of 62 girls had entered menarche with a median age of 12 years. 
Table 1. Concomitant and median values of leptin concentrations and BMI SDS at baseline, after weight loss, and during follow-up in boys and girls

\begin{tabular}{|c|c|c|c|c|c|}
\hline & \multicolumn{2}{|l|}{ Day } & \multicolumn{3}{|l|}{ Month } \\
\hline & 1 & 82 & 10 & 16 & 28 \\
\hline \multicolumn{6}{|l|}{ Boys } \\
\hline Number $^{\mathrm{a}}$ & $45(47)$ & $33(41)$ & $25(27)$ & $17(23)$ & $18(23)$ \\
\hline $\begin{array}{l}\text { BMI SDS } \\
\quad(5 \text { and } 95 \% \text { percentiles })\end{array}$ & $\begin{array}{l}2.8 \\
(1.7 ; 3.6)\end{array}$ & $\begin{array}{l}1.8 \\
(0.8 ; 2.8)\end{array}$ & $\begin{array}{l}2.2 \\
(0.3 ; 3.2)\end{array}$ & $\begin{array}{l}2.3 \\
(1.3 ; 3.4)\end{array}$ & $\begin{array}{l}2.4 \\
(1.4 ; 3.4)\end{array}$ \\
\hline $\begin{array}{l}\text { Leptin, } \mathrm{ng} / \mathrm{ml} \\
\quad(5 \text { and } 95 \% \text { percentiles })\end{array}$ & $\begin{array}{l}21.1 \\
(8.7 ; 34.8)\end{array}$ & $\begin{array}{l}4.4 \\
(2.9 ; 9.9)\end{array}$ & $\begin{array}{l}10.2 \\
(1.5 ; 34.3)\end{array}$ & $\begin{array}{l}8.8 \\
(1.9 ; 26.2)\end{array}$ & $\begin{array}{l}9.8 \\
(3.8 ; 27.1)\end{array}$ \\
\hline Partial $\mathrm{r}^{\mathrm{b}}$ & 0.56 & 0.14 & 0.49 & 0.66 & 0.38 \\
\hline $\mathrm{P}$ & $<0.0001$ & 0.45 & 0.017 & 0.007 & 0.15 \\
\hline \multicolumn{6}{|l|}{ Girls } \\
\hline Number $^{\mathrm{a}}$ & $44(51)$ & $32(45)$ & $29(29)$ & $30(32)$ & $18(21)$ \\
\hline $\begin{array}{l}\text { BMI SDS } \\
\quad(5 \text { and } 95 \% \text { percentiles })\end{array}$ & $\begin{array}{l}2.7 \\
(1.8 ; 3.3)\end{array}$ & $\begin{array}{l}1.8 \\
(0.7 ; 2.8)\end{array}$ & $\begin{array}{l}2.1 \\
(1.2 ; 3.1)\end{array}$ & $\begin{array}{l}2.4 \\
(1.2 ; 3.3)\end{array}$ & $\begin{array}{l}2.5 \\
(1.1 ; 3.5)\end{array}$ \\
\hline $\begin{array}{l}\text { Leptin, } \mathrm{ng} / \mathrm{ml} \\
\quad(5 \text { and } 95 \% \text { percentiles) }\end{array}$ & $\begin{array}{l}27.8 \\
(15.5 ; 58.4)\end{array}$ & $\begin{array}{l}8.8 \\
(4.5 ; 22.6)\end{array}$ & $\begin{array}{l}22.7 \\
(9.8 ; 43.0)\end{array}$ & $\begin{array}{l}25.6 \\
(7.9 ; 51.1)\end{array}$ & $\begin{array}{l}28.7 \\
(13.3 ; 43.7)\end{array}$ \\
\hline Partial $\mathrm{r}^{\mathrm{b}}$ & 0.56 & 0.52 & 0.63 & 0.83 & 0.43 \\
\hline p-value & $<0.0001$ & 0.0032 & 0.004 & $<0.0001$ & 0.094 \\
\hline
\end{tabular}

${ }^{a}$ Numbers shown refer to children with concomitant measures of BMI SDS, leptin, insulin and puberty. Numbers in brackets refer to children with measures of BMI SDS and leptin only. ${ }^{b}$ The partial Pearson correlation coefficients (r) between leptin and BMI SDS were adjusted for insulin and testicular size in boys, and insulin and menarche or not in girls.
Table 2. The leptin and BMI SDS relationship was expressed by regression coefficients with corresponding standard errors (SE) at baseline, after weight loss, and during follow-up in obese boys and in $\operatorname{girls}^{\mathrm{a}}$

\begin{tabular}{|c|c|c|c|c|c|c|}
\hline & \multicolumn{3}{|l|}{ Boys } & \multicolumn{3}{|l|}{ Girls } \\
\hline & number & regression coefficient $\pm \mathrm{SE}$ & p-value & number & regression coefficient $\pm \mathrm{SE}$ & p-value \\
\hline Day 1 & 47 & $0.52 \pm 0.11$ & & 51 & $0.49 \pm 0.10$ & \\
\hline Day 82 & 41 & $0.32 \pm 0.10$ & 0.07 & 45 & $0.42 \pm 0.09$ & 0.51 \\
\hline Month 10 & 27 & $0.81 \pm 0.09$ & 0.0007 & 29 & $0.43 \pm 0.11$ & 0.50 \\
\hline Month 16 & 23 & $0.58 \pm 0.12$ & 0.54 & 32 & $0.66 \pm 0.10$ & 0.082 \\
\hline Month 28 & 23 & $0.35 \pm 0.13$ & 0.058 & 20 & $0.30 \pm 0.11$ & 0.11 \\
\hline
\end{tabular}

${ }^{a}$ Log-transformed leptin concentrations were modelled using a multiple linear model with correlated errors [23]. An interaction term allows the association at later examinations were compared with the association between leptin and BMI SDS to change over time where the associations at later examinations were compared to the association at baseline. The analyses were adjusted for testicular size in boys and menarche in girls. The reported p-values are for testing whether regression coefficients at baseline were similar to the regression coefficients at subsequent follow-up measurements.
There was an inverse relationship between leptin and testicular size (regression coefficient $\beta=-0.331 \pm 0.054 ; \mathrm{p}<0.0001$ ).

Owing to the availability of a more complete data set for BMI SDS than for fat mass percentage, we used BMI SDS in the analysis, but all established relationships were confirmed using fat mass percentage.

Table 1 shows median BMI SDS and leptin levels and 5 and 95\% percentiles at baseline, after weight loss, and during follow-up in boys and girls. Median BMI SDS decreased by 1.0 in boys, and by 0.9 in girls during weight loss, but increased by 0.6 in boys and by 0.7 in girls during follow-up. Median leptin levels decreased by $16.7 \mathrm{ng} / \mathrm{ml}$ in boys and by $19.0 \mathrm{ng} / \mathrm{ml}$ in girls during weight loss, but increased by $5.4 \mathrm{ng} / \mathrm{ml}$ in boys and by $19.9 \mathrm{ng} / \mathrm{ml}$ in girls during weight regain. Partial correlation co- efficients $(r)$ (adjusted for puberty and insulin levels) between leptin and BMI SDS were stronger for girls than for boys.

Table 2 shows regression coefficients derived from the relationship between leptin and BMI SDS in boys and girls at baseline, after weight loss, and during follow-up. The regression coefficients and corresponding standard errors expressing the leptin-BMI SDS relationship were more similar and stable in girls than in boys. The regression coefficients expressing the leptin-BMI SDS relationship were adjusted for testicular size in boys and for menarche in girls.

Figure 1 shows relative changes of leptin compared to concomitant relative changes of BMI SDS during weight regain in boys and girls. Regression coefficients and confidence intervals expressing the relationship between leptin concentrations 

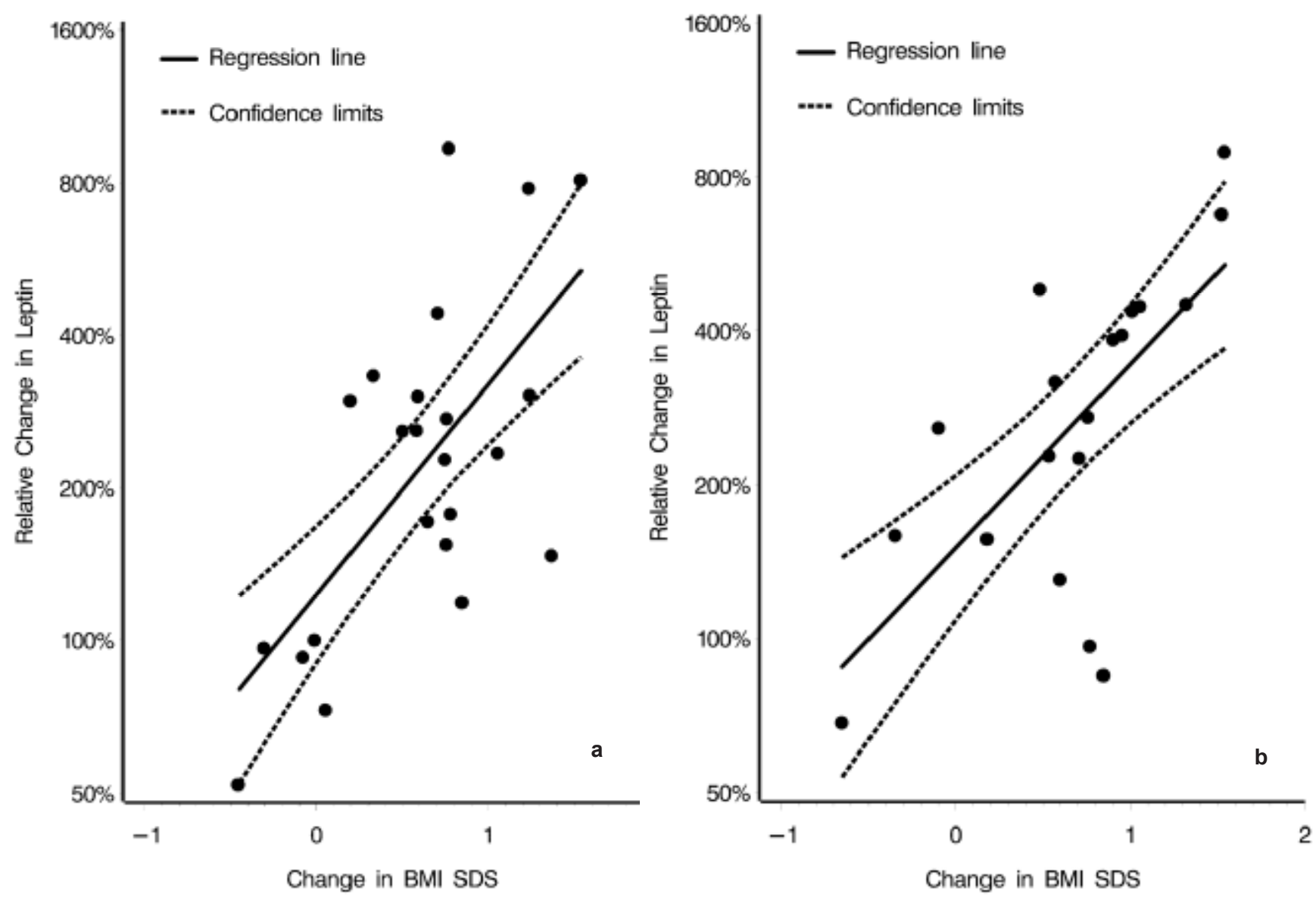

Fig. 1. Large increases in BMI SDS were accompanied by large relative increases in leptin concentrations during weight regain in $\mathbf{a}$ boys and $\mathbf{b}$ girls. The relationship between concomitant relative changes in leptin and BMI SDS were significant, and alike between the genders during weight regain. BMI SDS. Regression lines expressing the relationship between leptin and BMI SDS (-) and confidence 2.5 and $97.5 \%$ limits (----) are shown. Regression coefficients and confidence intervals expressing the relationship between leptin concentrations and BMI SDS were 2.3 (95\% CI 1.4-3.6) in boys, $(\mathrm{p}=0.0006)$ and $2.6(95 \%$ CI 1.6-4.3) in girls, $(\mathrm{p}=0.0016)$.

and BMI SDS were $2.3(95 \%$ CI 1.4-3.6) in boys, $(\mathrm{p}=0.0006)$ and $2.6(95 \%$ CI 1.6-4.3) in girls, $(\mathrm{p}=0.0016)$. Those children with the greatest BMI SDS increases also exhibited the largest leptin increments.

Table 3 shows leptin during follow-up adjusted for puberty and BMI SDS. Leptin changes (measured) were compared with expected (calculated) values derived from the baseline relationship between leptin, BMI SDS, and puberty and given the subsequent changes in puberty and BMI SDS during follow-up. The leptin concentrations seen during follow-up were compatible with the leptin-BMI SDS relationship established at baseline. However, the second follow-up examination in boys showed significantly lower leptin concentrations than expected.

\section{Discussion}

The results of the present study show that those children with the greatest BMI SDS increases also exhibited the larg- est increases in leptin concentration, suggesting an intact leptin response to weight regain in children. During weight regain leptin concentrations recovered quickly and mirrored BMI SDS elevations reaching a relationship with BMI SDS during weight regain, which was comparable to that at baseline. These findings do not support the view that disproportionally decreased leptin seen during weight loss persist during weight regain, and thereby possibly contributing to the regain.

A number of limitations should be noted. First, attrition in numbers was substantial but did not prevent the establishment of significant partial correlation for the leptin-BMI relationships. Children dropping out were not different in terms of baseline age or BMI SDS to those remaining, as suggested by the fact that re-analysis excluding those dropping out gave similar results. It is likely that poor retention during follow-up is associated with poor maintenance of weight. If this was true, those children remaining in the study would be those with relatively better weight maintenance, which suggests that the found relationships between 
Table 3. Measured leptin concentrations versus expected leptin concentrations ${ }^{\mathrm{a}}$

\begin{tabular}{llll}
\hline \multicolumn{5}{c}{} & Leptin concentrations & & \\
\cline { 2 - 4 } & $\begin{array}{l}\text { percentage of } \\
\text { expected }\end{array}$ & confidence interval, \% & p-value \\
\hline Boys & & & \\
Baseline & 100 & $71-105$ & 0.14 \\
Month 10 & 86 & $59-93$ & 0.01 \\
Month 16 & 74 & $85-124$ & 0.74 \\
Month 28 & 103 & & 0.79 \\
\hline Girls & & & 0.66 \\
Baseline & 100 & $86-113$ & 0.55 \\
Month 10 & 98 & $87-109$ & \\
Month 16 & 98 & $78-115$ & \\
Month 28 & 94 & & \\
\hline
\end{tabular}

${ }^{\text {a}}$ Follow-up measured leptin concentrations are alike to baseline, except for the second follow-up estimate in boys, which is lower. p-values express whether measured leptin concentrations during follow-up were similar to expected follow-up concentrations of leptin. Expected leptin concentrations were calculated given the relationship of leptin, BMI SDS, and puberty at baseline and given the subsequent changes of BMI SDS and puberty during follow-up.

Expected leptin concentrations were generated by a longitudinal multiple linear model with correlated errors [23].

leptin and BMI SDS seems more likely attenuated than inflated. However, it is not uncommon that pediatric weight management studies report retention rates ranging from 20 to $50 \%$ [25], while our retention rate of $78 \%$ during weight loss and $65 \%$ during follow-up can be considered as a relative satisfying result.

The present study also suggests sex differences in the associations since the partial correlations between leptin and BMI SDS were stronger and more stable in girls. Divergent gonadal steroids and body composition during puberty have been found to contribute to the sexual dimorphism seen in leptin levels [26]. However, body composition and puberty were accounted for in the longitudinal multivariate modelling in the present study, which did not alter the discrepancies between expected and measured leptin concentrations in either boys or girls. Our findings are thus in agreement with Nagy et al. [27] who found that differences in body composition (though measured by dual energy X-ray absorptiometry) did not explain the sexual dimorphism seen in leptin levels, as it was also shown by Wabitsch et al. [28]. However, in the study by Nagy et al. [27], adjustment of both body composition and body fat distribution explained the difference in leptin concentrations seen between the genders. Further, the difference seen in leptin concentrations between boys and girls can be reversed by hormone replacement therapy; in trans-sexuals it was demonstrated that the sexual dimorphism seems to be influenced by the sex steroid milieu, and only to a lesser extent by the genetic sex [29]. Thus, leptin is likely to be de- pendent on sex steroids, but the effect of sex steroids on body composition seems to be less important than that on leptin concentrations.

Studies on concurrent increases in weight and leptin are scarce, permitting comparison of such studies only to a limited extent. In anorexia nervosa, leptin levels have been found to be low in untreated anorectics and to increase during re-feeding and weight gain [8, 11-13, 30]. Interestingly, Eckert et al. [8] found that leptin and BMI did not correlate in those anorectics with an extremely low BMI during starvation, whereas a significant correlation was found after weight gain. The anorectics with extremely low body weights are on the edge of survival, and the leptin-BMI relationship might be distorted and outside the normal range of biologic regulation. When the weight normalizes the leptin-BMI relationship seems to be restored [9], and the leptin-BMI relationship also seems to be preserved during obesity as suggested by the findings in the present study. There are other repeat studies of leptin before and after weight gain in children with chronic diseases, e.g. children with type 1 diabetes mellitus (intensified insulin therapy causing hyperinsulinemia with high leptin levels) [14], malnourished children experiencing weight gain [15], children with mild protein energy malnutrition with subsequent catch-up growth [16], risperidone-treated youth with autism [19], or epileptic children treated with valproate [31]. In general, weight gains seems accompanied by increases in leptin concentrations, but these studies have generally not studied leptin dependency upon weight in consecutive measurements during weight gain.

Savoye et al. [7] investigated concomitant changes in leptin concentrations and weight among 68 obese boys and girls at baseline and after 2.5 years. A significant positive correlation was found between leptin levels and BMI at baseline, and a high baseline leptin level predicted weight gain in girls. In this study girls had higher leptin levels than boys; however, no net weight gain was observed before and after these 2.5 years, that is why it is difficult to compare the data with our analysis of concomitant increases of both BMI SDS and leptin concentrations. Furthermore, Kettaneh et al. [4] studied 404 children during 2 years, and Fleisch et al. [5] investigated 197 children with an average follow-up of 4.4 years. Both studies found that those with high leptin levels relative to fat mass at baseline gained more fat mass over time [4] in both sexes [5], a finding which may be an indicator of increased leptin resistance [5].

In summary, we found corresponding increases of both leptin and BMI SDS during 31 months of weight regain. These findings suggest an intact leptin response after weight loss and during weight regain and does not lend support that weight regain is promoted by a continued disproportionally lowered leptin level during weight regain. However, even before all weight was regained, the leptin levels returned to baseline values, suggesting that leptin may not act as a strong satiety response to prevent further weight regain. These findings 
highlight the importance of a continued search for the factors contributing to the regulation of weight progression and maintenance.

\section{Acknowledgements}

This work has generously been supported by grants from P Carl Petersens Foundation, The Health Insurance Foundation, The Christmas Stamp Foundation, The Danish Hospital Foundation for Medical Research. Region of Copenhagen, The Faeroe Islands and Greenland, Danish Medical Research Council, The Queen Louises Children's Hospital Research
Foundation, The King Christian the X'th Foundation, Managing Director Ib Henriksens Foundation, The Rosalie Petersen Foundation, The Glasshoff Foundation, Novo Nordic Foundation and The Dagmar Marshall Foundation.

Further, Mrs. Oda Troest has provided invaluable expert assistance regarding data retrieving and handling.

\section{Disclosure}

T.I.A.S. collaborates with Nestlé Research Centre, Lausanne, and DSM, The Netherlands, on obesity research.

\section{References}

1 Flier JS: Clinical review 94: What's in a name? In search of leptin's physiologic role. J Clin Endocrinol Metab 1998;83:1407-1413.

2 Schwartz MW, Woods SC, Seeley RJ, Barsh GS, Baskin DG, Leibel RL. Is the energy homeostasis system inherently biased toward weight gain? Diabetes 2003:52:232-238.

3 Ravussin E, Pratley RE, Maffei M, Wang H, Friedman JM, Bennett PH, et al: Relatively low plasma leptin concentrations precede weight gain in Pima Indians. Nat Med 1997;3:238-240.

4 Kettaneh A, Heude B, Romon M, Oppert J, Borys J, Balkau B, et al: High plasma leptin predicts an increase in subcutaneous adiposity in children and adults. Eur J Clin Nutr 2007;61:719-726.

$\checkmark 5$ Fleisch A, Agarwal N, Roberts M, Han J, Theim K, Vexler A, et al: Influence of serum leptin on weight and body fat growth in children at high risk for adult obesity. J Clin Endocrinol Metab 2007;92:948-954.

6 Holm J-C, Gamborg M, Ibsen KK, Gammeltoft S, Ward L, Heitmann BL, et al: Time course and determinants of leptin decline during weight loss in obese boys and girls. Int J Ped Obes 2007;2:2-10.

7 Savoye M, Dziura J, Castle J, DiPietro L, Tamborlane WV, Caprio S: Importance of plasma leptin in predicting future weight gain in obese children: a two-and-a-half-year longitudinal study. Int J Obes Relat Metab Disord 2002;26:942-946.

$>8$ Eckert ED, Pomeroy C, Raymond N, Kohler PF, Thuras P, Bowers CY: Leptin in anorexia nervosa. J Clin Endocrinol Metab 1998:83:791-795.

$\checkmark$ Balligand JL, Brichard SM, Brichard V, Desager JP, Lambert M: Hypoleptinemia in patients with anorexia nervosa: loss of circadian rhythm and unresponsiveness to short-term refeeding. Eur J Endocrinol 1998;138:415-420.

10 Herpertz S, Albers N, Wagner R, Pelz B, Kopp W, Mann K, et al: Longitudinal changes of circadian leptin, insulin and cortisol plasma levels and their correlation during refeeding in patients with anorexia nervosa. Eur J Endocrinol 2000;142:373-379.

11 Lob S, Pickel J, Bidlingmaier M, Schaaf L, Backmund $\mathrm{H}$, Gerlinghoff M, et al: Serum leptin monitoring in anorectic patients during refeeding therapy. Exp Clin Endocrinol Diabetes 2003;111:278-282.
12 Holtkamp K, Hebebrand J, Mika C, Heer M, Heussen N, Herpertz-Dahlmann B: High serum leptin levels subsequent to weight gain predict renewed weight loss in patients with anorexia nervosa. Psychoneuroendocrinology 2004;29:791-797.

13 Haas V, Onur S, Paul T, Nutzinger D, Bosy-Westphal A, Hauer M, et al: Leptin and body weight regulation in patients with anorexia nervosa before and during weight recovery. Am J Clin Nutr 2005; 81:889-896.

14 Verrotti A, Basciani F, De Simone M, Morgese G, Chiarelli F: Leptin concentration in non-obese and obese children with type 1 diabetes mellitus. Biomed Pharmacother 2000;54:69-73.

15 Palacio AC, Pérez-Bravo F, Santos JL, Schlesinger L, Monckeberg F: Leptin levels and IgF-binding proteins in malnourished children: effect of weight gain. Nutrition 2002;18:17-19.

16 Büyükgebiz B, Oztürk Y, Yilmaz S, Arslan N: Serum leptin concentrations in children with mild proteinenergy malnutrition and catch-up growth. Pediatr Int 2004;46:534-538.

17 Ahmed M, Ong K, Thomson A, Dunger D: Reduced gains in fat and fat-free mass, and elevated leptin levels in children and adolescents with cystic fibrosis. Acta Paediatr 2004;93:1185-1191.

18 Atmaca M, Kuloglu M, Tezcan E, Ustundag B: Weight gain and serum leptin levels in patients on lithium treatment. Neuropsychoendocrinology 2002; 46:67-69.

19 Martin A, Scahill L, Anderson G, Aman M, Arnold L, McCracken J, et al: Weight and leptin changes among risperidone-treated youths with autism: 6-month prespective data. Am J Psychiatry 2004; 161:1125-1127.

20 Nysom K MC, Hutchings B, Michaelsen KF: Body mass index of 0 to 45 -y-old Danes: reference values and comparison with published European reference values. Int J Obes Relat Metab Disord 2001;25: 177-184.

21 Schaefer F, Georgi M, Zieger A, Scharer K: Usefulness of bioelectric impedance and skinfold measurements in predicting fat-free mass derived from total body potassium in children. Pediatr Res 1994; 35:617-624.
2 Wabitsch M, Braun U, Heinze E, Muche R, Mayer $\mathrm{H}$, Teller W, Fusch C: Body composition in 5-18-yold obese children and adolescents before and after weight reduction as assessed by deuterium dilution and bioelectrical impedance analysis. Am J Clin Nutr 1996;64:1-6.

23 Diggle P, Heagerty P, Liang K-Y, Zeger S: Analysis of Longitudinal Data, 2nd ed. Oxford, Oxford University Press, 2002

24 Molenberghs G, Kenward MG: Missing Data in Clinical Studies. Chichester, John Wiley and Sons, 2007.

25 Summerbell K, Ashton V, Campbell K, Edmunds L, Kelley S, Waters E: Interventions for treating children. Cochrane Database Syst Rev 2003;3: CD001872.

26 Ahmed ML, Ong KK, Morrell DJ, Cox L, Drayer $\mathrm{N}$, Perry L, et al: Longitudinal study of leptin concentrations during puberty: sex differences and relationship to changes in body composition. J Clin Endocrinol Metab 1999;84:899-905.

27 Nagy TR, Gower BA, Trowbridge CA, Dezenberg C, Shewchuk RM, Goran MI: Effects of gender, ethnicity, body composition, and fat distribution on serum leptin concentrations in children. J Clin Endocrinol Metab 1997;82:2148-2152.

28 Wabitsch M, Blum WF, Muche R, Braun M, Hube F, Rascher W, et al: Contribution of androgens to the gender difference in leptin production in obese children and adolescents. J Clin Invest 1997;100: 808-813.

29. Elbers JM, Asscheman H, Seidell JC, Frolich M, Meinders AE, Gooren LJ: Reversal of the sex difference in serum leptin levels upon cross-sex hormone administration in transsexuals. J Clin Endocrinol Metab 1997;82:3267-3270.

30 Herpertz S, Wagner R, Albers N, Blum WF, Pelz B, Langkafel M, et al: Circadian plasma leptin levels in patients with anorexia nervosa: relation to insulin and cortisol. Horm Res 1998;50:197-204.

31 Caksen H, Deda G, Berberoglu M: Does long-term use of valproate cause weight gain in prepubertal epileptic children? Int J Neuroscience 2002;112: 1183-1189. 